
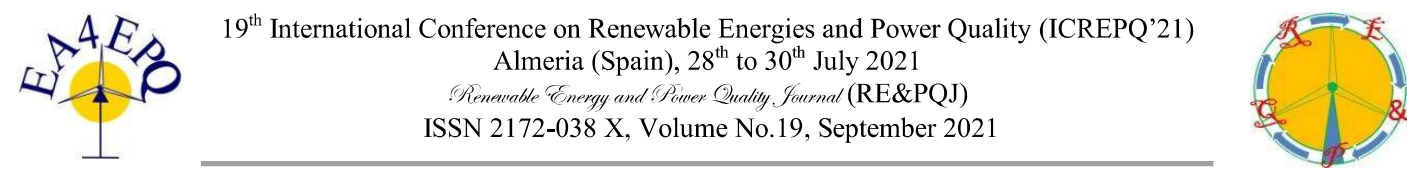

\title{
Optimisation of Energy Accumulation for Renewable Energy Sources
}

\author{
M. Belik \\ Department of Power Engineering \\ Faculty of Electrical Engineering, University of West Bohemia \\ Univerzitni 8, 30614 Pilsen (Czech Republic) \\ Phone/Fax number:+00420 377 634315, e-mail: belik4@fel.zcu.cz
}

\begin{abstract}
This project focuses on optimisation of energy accumulation for various types of distributed renewable energy sources. The main goal is to prepare charging - discharging strategy depending on actual power consumption and prediction of consumption and production of utilised renewable energy sources for future period. The simulation is based on real long term data measured on photovoltaic system, wind power station and meteo station between 2004 - 2021. The data from meteo station serve as the input for the simulation and prediction of the future production while the data from PV system and wind turbine are used either as actual production or as a verification of the predicted values. Various parameters are used for trimming of the optimisation process. Influence of the charging strategy, discharging strategy, values and shape of the demand from the grid and prices is described on typical examples of the simulations. The main goal is to prepare and verify the system in real conditions with real load chart and real consumption defined by the model building with integrated renewable energy sources. The system can be later used in general installations on commercial or residential buildings.
\end{abstract}

Key words. renewable energy sources, accumulation systems, charging - discharging strategy, optimisation.

\section{Introduction}

Selected data measured on particular components of the Renewable Energy Sources Minipark installed on the roof of the faculty building are used for the purposes of this study,. First, there are values of solar radiation intensity, wind speed and direction, temperature and other meteorological variables from the meteorological station, which serve as the input data of our algorithm for production prediction in the future period. The values of real production from photovoltaic power plants and wind power plants serve as the input data of the algorithm for simulation of real production from particular RES and to verify the predicted production $[1,2]$.

All these data are prepared as characteristic courses or values for the period from 2004 to 2020 , so they can be considered with sufficient accuracy as a representative sample describing the behavior of real systems and the situation in the real location. The range of these data is

This paper was supported by SGS-2021-018. particularly important to rule out errors caused by climate fluctuations over particular years. This eliminates any possible underestimation or overestimation of production from individual types of RES in the localion. Due to the scope and variability of the input data, the characteristic courses of production from both sources and individual meteorological variables for particular seasons were determined for the purposes of the study from the whole set. In the case of a photovoltaic system, it means a sunny day, a cloudy day and a day with variable clouds. This selection allows the simulation of variants of the current production and the prediction of the next day displayed in Tab. I.

Tab. I: Production and prediction from PV station

\begin{tabular}{|l|l|l|l|l|l|l|}
\hline pruduc & sunny & sunny & sunny & cloudy & cloudy & cloudy \\
\hline predict & sunny & cloudy & $1 / 2$ & sunny & cloudy & $1 / 2$ \\
\hline
\end{tabular}

Although the waveforms are similar for each period, they differ in the total supplied energy and mainly by the different time shift from the consumption diagram. So it is not possible to limit the selection to characteristic "annual" waveforms with sufficient accuracy, although it would significantly reduce the total number of particular simulations [2].

Similarly for the wind power plant, the characteristic courses for a windy day, a day with no wind and a day with variable wind were determined. Individual combinations of current production and forecasts for the next day are listed in Tab. II.

Tab.I I: Production and prediction from PV station

\begin{tabular}{|l|l|l|l|l|l|l|}
\hline pruduc & wind & wind & wind & zero & zero & zero \\
\hline predict & wind & zero & $1 / 2$ & wind & zero & $1 / 2$ \\
\hline
\end{tabular}

\section{Input data - PV station production}

$20 \mathrm{kWp}$ photovoltaic system is installed on the roof of the classroom building of the Faculty of Electrical Engineering in Bory. This system serves not only for experimental purposes, but also permanently supplies energy to the school network, which ideally meets the input requirements of this study. The power plant was 
commissioned during 2004 and has been continuously monitored since the beginning [3].

192 pieces of the Isofoton I 110 monocrystalline silicon panels with total output of $21120 \mathrm{Wp}$ are used in the experimental PV power plant. The panels are coupled into eight separate strings (photovoltaic assembly E1 - E8). Each string contains 24 panels connected in three branches by eight panels (series-parallel connection of $3 \times 8$ panels).

The energy from the PV panels is fed via relatively long DC lines to the central inverter room. This topology is characteristic to the time of the commissioning. Although this solution is less energy efficient, it is interesting for the purposes of this study, as it is typical for older systems that are expected to be replenishment with battery systems [4].

Each string is connected to its own single-phase Sun Power SunProfi SP2500-450 inverter with output voltage of $230 \mathrm{~V}, 50 \mathrm{~Hz}$, which are automatically phased to the grid via the RDAC switchboard to particular phases. The configuration is described in Table III.

Tab. III: String configuration (E1 - E8)

\begin{tabular}{|l|l|l|l|l|}
\hline String & Number & Type & Branch & Inverter \\
\hline E1-E8 & 24 & I-110 & 3 & SP 2500-450 \\
\hline
\end{tabular}

Measure parameters:

- intensity on PV panels $\left[\mathrm{W} / \mathrm{m}^{2}\right]$

- temperature of the I sensor $\left[{ }^{\circ} \mathrm{C}\right]$

- intensity on horizontal plane $\left[\mathrm{W} / \mathrm{m}^{2}\right]$

- temperature of PV panels $\left[{ }^{\circ} \mathrm{C}\right]$

- $\quad$ current - string no. 8 [A]

- $\quad$ voltage - string no. $8[\mathrm{~V}]$

- power - string no. $8[\mathrm{~W}]$

- ambient temperature $\left[{ }^{\circ} \mathrm{C}\right]$

- total production $[\mathrm{kWh}]$

All measured values are stored in 10 min intervals. Average, minimum and maximum value of each quantity is recorded. Data is stored in daily files after each calendar day.

The meteo station stores the meteorological values in 1 minute interval. These data are used for the purposes of the study as input values for the prediction of production during the following day. The calculation can be then verified on the real data measured on the photovoltaic system [5].

From the long-term values (2004 - 2021) measured at the experimental photovoltaic power plant, characteristic production courses for a sunny, cloudy and variable day were selected for all seasons. These waveforms were used as input values of current production to verify the functionality of the tested algorithm. Figure 1 shows typical course of production during a spring variable and cloudy day.

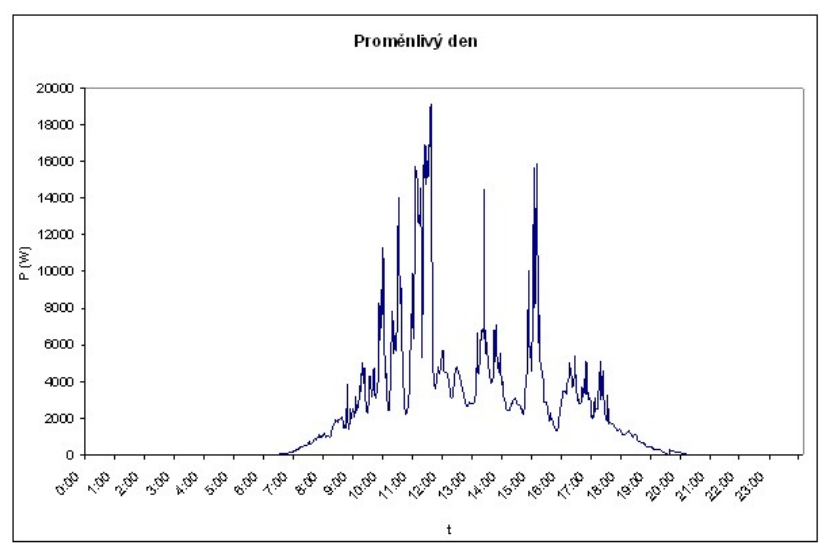

Fig. 1. PV production (typical spring variable day).

\section{Input data - PV station prediction}

The values of global radiation obtained from the meteo station must be recalculated to the surface of the photovoltaic plant (orientation south, inclination $45^{\circ}$ ) to determine the production prediction. For the purposes of this study, the methodology using a conversion from the global radiation first to the normal component and then to the generally oriented area. The total intensity of solar radiation is expressed from the arithmetic sum of the direct and diffuse components:

$$
I=I_{P}+I_{D} \quad\left[\mathrm{~W} / \mathrm{m}^{2}\right]
$$

The measured values of global radiation can be similarly decomposed into the sum of the direct and diffuse components on a horizontal surface:

$$
I_{G}=I_{P h}+I_{D h} \quad\left[\mathrm{~W} / \mathrm{m}^{2}\right]
$$

where $I_{P h}$ represents the intensity of the direct sunlight incidenting on a horizontal surface, which can be expressed as:

$$
I_{P h}=I_{P n} \sin h \quad\left[\mathrm{~W} / \mathrm{m}^{2}\right]
$$

and $\mathrm{I}_{\mathrm{Dh}}$ represents the intensity of diffuse radiation incident on a horizontal surface, which is defined by:

$$
I_{D h}=0,33\left(I_{0}-I_{P n}\right) \sin h \quad\left[\mathrm{~W} / \mathrm{m}^{2}\right]
$$

The value of the normal component $\mathrm{I}_{\mathrm{Pn}}$ can be expressed from the equations 2, 3 and 4 . The calculation can be also verified by conversion from the solar constant $\mathrm{I}_{0}$ and the pollution factor Z:

$$
I_{P n}=I_{0} e^{-\frac{Z}{\varepsilon}} \quad\left[\mathrm{W} / \mathrm{m}^{2}\right]
$$

where $\varepsilon$ is the dimensionless coefficient depending on the altitude of the locality and the height of the Sun above the horizon expressed as:

$$
\varepsilon=\frac{9,38076\left[\sin h+\left(0.003+\sin ^{2} h\right)^{0.5}\right]}{2.0015\left(1-H \cdot 10^{-4}\right)}+0.91018
$$

where $\mathrm{H}$ is the altitude of the site in meters and $\mathrm{h}$ is the height of the sun above the horizon. For the model object (UWB Pilsen) is the altitude $353 \mathrm{~m}$ above sea level. The height of the Sun above the horizon is calculated: 
$\sin h=\sin \delta^{*} \sin \varphi+\cos \delta^{*} \cos \varphi^{*} \cos \tau$

where $\varphi$ is the latitude value of the site (for the model object: $\left.49^{\circ} 43^{\prime} 22^{\prime \prime}\right)$. The value of $\tau$ indicates a time angle of $15^{\circ}$ for each full hour, with positive values from noon (south) to evening (west) and negative values towards morning (east). The value of $\sigma$ represents the solar declination for a given calendar day, which can be obtained exactly from astronomical yearbooks or determined for technical purposes by a simplified calculation according to ČSN 730581:

$$
\delta=23,45 * \sin (0,98 * D+29,7 * M-109)
$$

where $\mathrm{M}$ indicates the order of the calendar month in the year and D the order of the day of the month. From the normal value, the intensity of the direct component of solar radiation can finally be determined on a generally oriented surface:

$$
I_{p}=I_{P n} \cos \gamma \quad\left[\mathrm{W} / \mathrm{m}^{2}\right]
$$

if $\gamma$ is the actual angle of incidence of the rays on the sunlit surface, expressed as:

$\cos \gamma=\sinh . \cos \alpha+\cosh \sin \alpha \cos \left(a-a_{s}\right)$

where $\alpha$ is the angle of inclination of the illuminated surface from the horizontal plane $\left(45^{\circ}\right.$ for the model object) and $a_{s}$ is the azimuth angle of the normal of the illuminated surface measured with the same orientation as the time angle $\tau\left(0^{\circ}\right.$ for the model object). The value of a represents the azimuth of the sun (oriented in a similar way) and expressed by the relation:

$$
\sin a=\frac{\cos \delta}{\cos (h)} * \sin \tau
$$

The diffusion component of solar radiation on a generally oriented surface is determined from the relation:

$$
I_{D}=0,5(1+\cos \alpha) I_{D h}+0,5 r(1-\cos \alpha)\left(I_{P h}+I_{D h}\right)
$$

$$
\left[\mathrm{W} / \mathrm{m}^{2}\right](12)
$$

Tab. IV demonstrates calculated monthly averages, minimum and maximum values of the average daily values of solar radiation intensity in the model location and their comparison with the theoretical values $\mathrm{I}_{\text {teor }}$.

Tab. IV: Daily values of intensity (south, incl. $45^{\circ}$ )

\begin{tabular}{|l|r|r|r|r|r|r|}
\hline & I. & II. & III. & IV. & V. & VI. \\
\hline $\mathrm{I}_{\text {str̆ }}\left[\mathrm{W} / \mathrm{m}^{2}\right]$ & 388 & 456 & 551 & 564 & 589 & 587 \\
\hline $\mathrm{I}_{\max }\left[\mathrm{W} / \mathrm{m}^{2}\right]$ & 407 & 471 & 553 & 571 & 602 & 589 \\
\hline $\mathrm{I}_{\min }\left[\mathrm{W} / \mathrm{m}^{2}\right]$ & 381 & 449 & 448 & 557 & 586 & 583 \\
\hline $\mathrm{I}_{\text {teor }}\left[\mathrm{W} / \mathrm{m}^{2}\right]$ & 412 & 490 & 558 & 580 & 600 & 590 \\
\hline & VII. & VIII & IX. & X. & XI. & XII. \\
\hline $\mathrm{I}_{\text {str̆ }}\left[\mathrm{W} / \mathrm{m}^{2}\right]$ & 582 & 565 & 541 & 482 & 398 & 322 \\
\hline $\mathrm{I}_{\max }\left[\mathrm{W} / \mathrm{m}^{2}\right]$ & 586 & 573 & 552 & 485 & 403 & 329 \\
\hline $\mathrm{I}_{\min }\left[\mathrm{W} / \mathrm{m}^{2}\right]$ & 579 & 560 & 532 & 476 & 390 & 315 \\
\hline $\mathrm{I}_{\text {teor }}\left[\mathrm{W} / \mathrm{m}^{2}\right]$ & 600 & 580 & 558 & 490 & 412 & 344 \\
\hline
\end{tabular}

Tab. V shows the same situation for the energy density of incident radiation in the model locality and their comparison with the theoretical values of $\mathrm{E}_{\text {teor }}$.

Tab. V: Daily values of energy (south, incl. $45^{\circ}$ )

\begin{tabular}{|l|r|r|r|r|r|r|}
\hline & I. & II. & III. & IV. & V. & VI. \\
\hline$E_{\text {str̆ }}\left[\mathrm{kWh} / \mathrm{m}^{2}\right]$ & 3,21 & 4,72 & 6,12 & 7,54 & 8,32 & 9,26 \\
\hline $\left.\mathrm{E}_{\max } \mathrm{kWh} / \mathrm{m}^{2}\right]$ & 3,37 & 4,89 & 6,56 & 8,01 & 8,99 & 9,58 \\
\hline $\mathrm{E}_{\min }\left[\mathrm{kWh} / \mathrm{m}^{2}\right]$ & 3,12 & 4,68 & 6,04 & 7,17 & 8,01 & 9,01 \\
\hline $\mathrm{E}_{\text {teor }}\left[\mathrm{kWh} / \mathrm{m}^{2}\right]$ & 3,40 & 4,96 & 6,70 & 8,06 & 9,42 & 9,64 \\
\hline & VII. & VIII & IX. & X. & XI. & XII. \\
\hline $\mathrm{E}_{\text {str̆ }}\left[\mathrm{kWh} / \mathrm{m}^{2}\right]$ & 9,11 & 7,87 & 6,45 & 482 & 398 & 322 \\
\hline $\left.\mathrm{E}_{\max } \mathrm{kWh} / \mathrm{m}^{2}\right]$ & 9,38 & 7,99 & 6,54 & 485 & 403 & 329 \\
\hline $\mathrm{E}_{\min }\left[\mathrm{kWh} / \mathrm{m}^{2}\right]$ & 8,78 & 7,64 & 6,38 & 476 & 390 & 315 \\
\hline $\mathrm{E}_{\text {teor }}\left[\mathrm{kWh} / \mathrm{m}^{2}\right]$ & 9,42 & 8,06 & 6,70 & 490 & 412 & 344 \\
\hline
\end{tabular}

From long-term values (2004 - 2021) measured from the meteorological station, in a similar way as in the case of production from a PV power plant, characteristic courses for a sunny, cloudy and variable day were selected for all seasons [3].

These waveforms were used as input values for the next day's production prediction to verify the functionality of the tested algorithm. Figure 2 shows typical course of production during a winter variable and cloudy day.

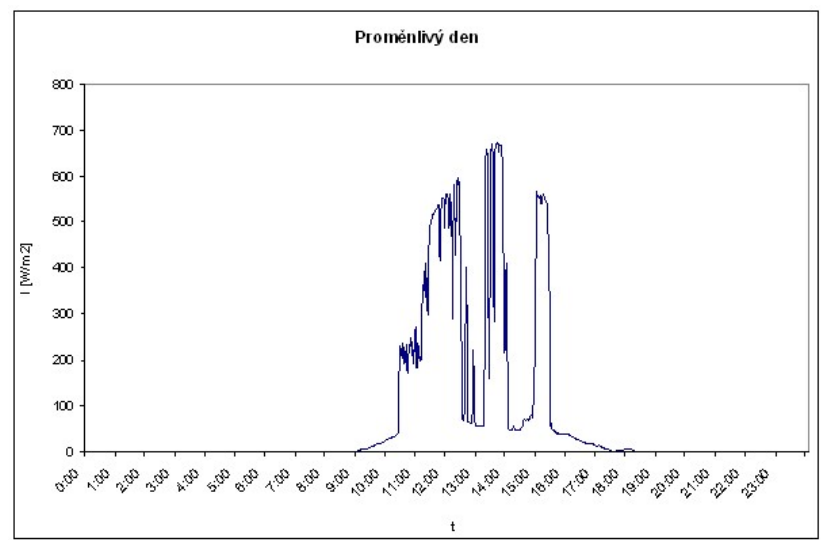

Fig. 2. Solar radiation (typical winter variable day).

When comparing the intensity curves in detail with the corresponding real production curves, certain deviations can be traced (especially in the case of rapid changes caused by variable cloud cover), which are mainly due to the current operating states of the inverters [5].

It is obvious that the intensity waveforms can be used with sufficient accuracy as input for the predictive part of the algorithm. The actual deviations for the waveforms on the Fig. 3 and 4 are shown on Figure 3. 


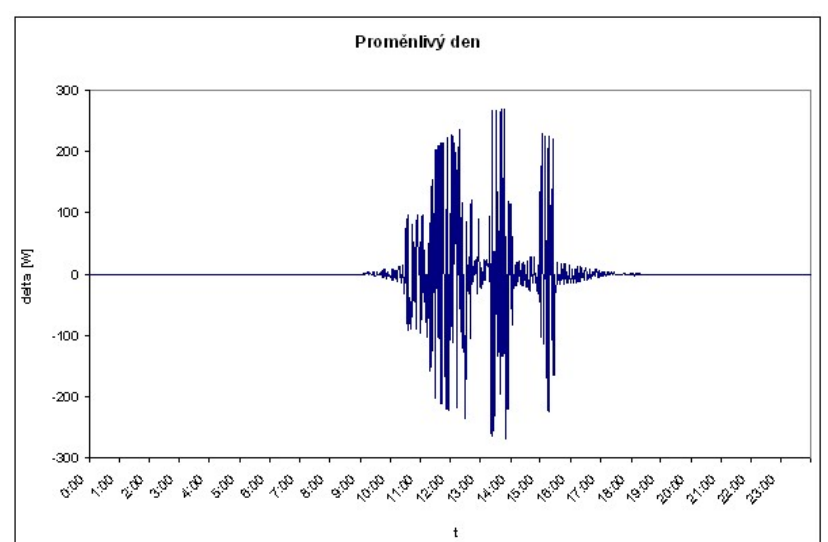

Fig. 3. Variation between production and prediction (typical winter variable day).

\section{Input data - eolic plant production}

A $500 \mathrm{~W}$ wind turbine is installed on the roof of the classroom building of the Faculty of Electrical Engineering in Bory. This system serves not only for experimental purposes, but also permanently supplies energy to the school network, which ideally meets the input requirements of this study. The power plant was commissioned in 2008, when it replaced the original 10 $\mathrm{kW}$ power plant. The power plant is, similarly to the photovoltaic system described above, continuously monitored from the commissioning. The AeroCraft AC 502 wind turbine consists of a three-bladed propeller with fixed blades and a controlled rudder. The generator is a three-phase 16-pole operating with a voltage of $24 \mathrm{~V}$ and connected via an inverter to the building network. It is a Type 3 wind turbine (sometimes referred to as DFIG or DFAG). This type is currently relatively common, as it has good regulatory capabilities and economic parameters. For these reasons, it is suitable for this study. The basic parameters of the used wind engine are:

- cut in wind speed: $3 \mathrm{~m} / \mathrm{s}$

- nominal wind speed: $9 \mathrm{~m} / \mathrm{s}$

- cut off wind speed: $40 \mathrm{~m} / \mathrm{s}$

The measurements of the turbine are logged in the interval 1 min. Power curve of the turbine is presented on Fig. 4.

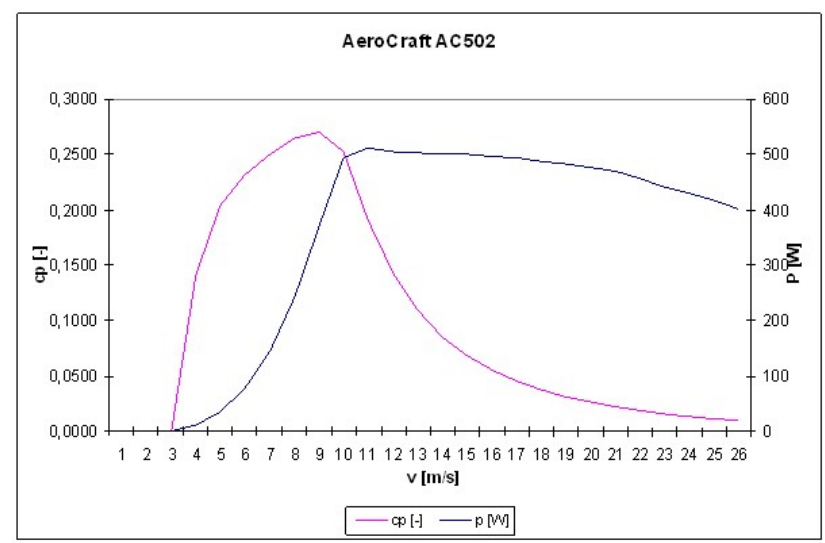

Fig. 4. Power curve (AeroCraft AC 502).

Characteristic production courses for a windy, calm and variable day were selected from measured long-term values (2008 - 2021). These waveforms are identical for all seasons and are used as input values of current production to verify the functionality of the tested algorithm. Figure 5 shows typical course of wind speed during a variable day.

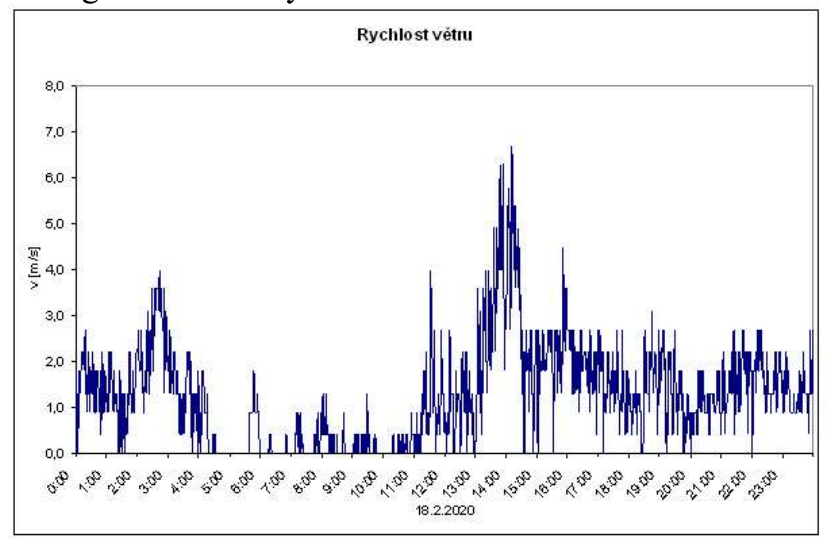

Fig. 5. Wind speed (typical calm day).

Figure 6 shows intervals when the turbine actually operates in the situation from Fig. 5.

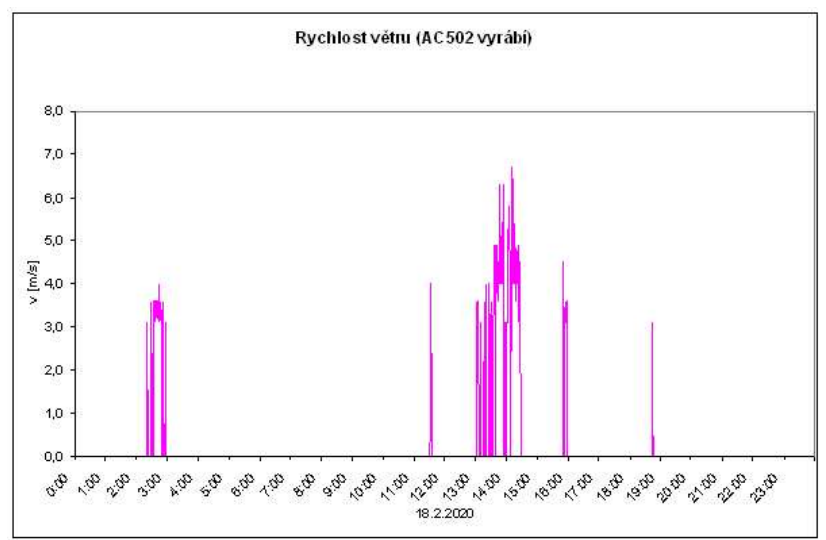

Fig. 6. Power production (typical calm day).

\section{Input data - eolic plant prediction}

Values of the wind speed obtained from the weather station must be recalculated to the area of the wind turbine propeller to determine the production prediction. For the purposes of this study, the methodology of calculation according to the power characteristic and the relevant values of the power factor $c_{p}$ was used. Figure 7 shows the values of the measured and recalculated power generation during typical windy day.

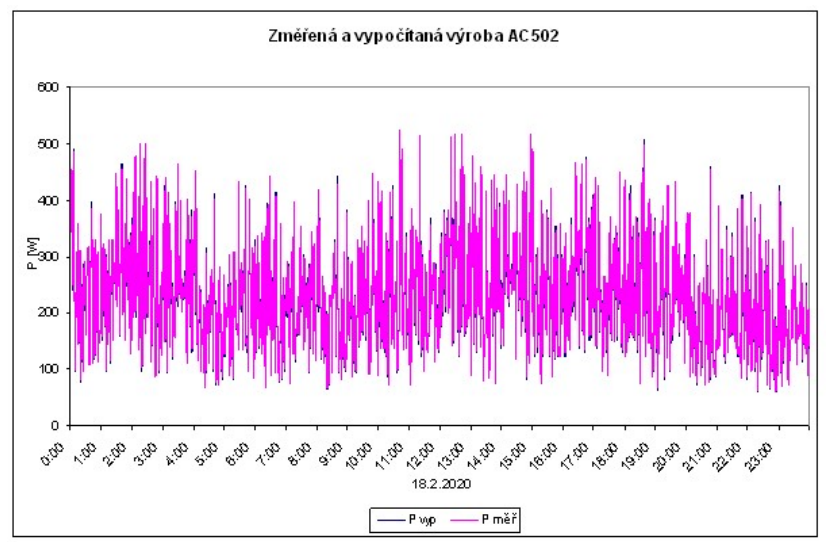

Fig. 7. Power production and prediction (typical windy day). 
It is evident from the waveforms shown on Fin. 7 that for the purposes of this study, or to verify the operation of production prediction using the tested algorithm, the data obtained are sufficiently accurate and representative.

Certain deviations can be traced in the detailed comparison of the calculated production curve with the corresponding real production curve. This is usually the result of the current state of generator excitation (ie its mechanical resistance) and the wind turbine's own inertial masses. The actual deviations for the courses during a and calm day is shown on Figure 8.

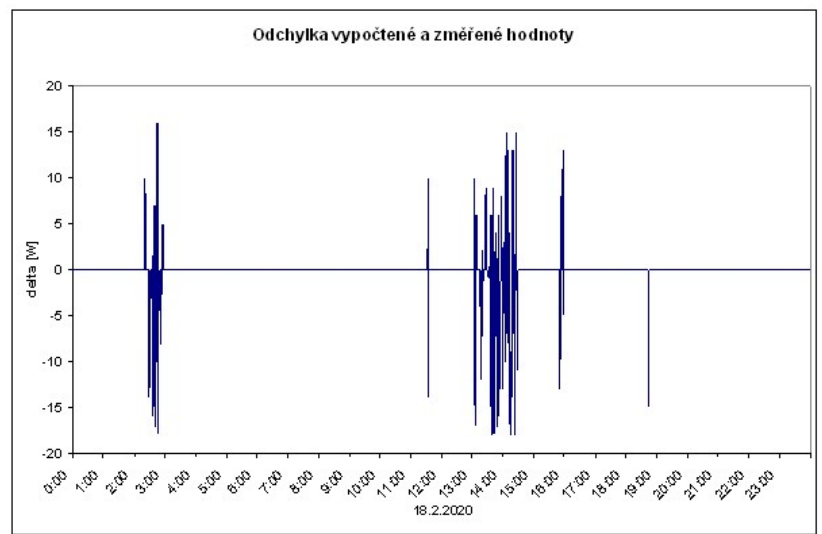

Fig. 8. Variation between production and prediction (typical calm day).

\section{Energy accumulation - battery system}

Set of 3 battery systems was designed for the purposes of this study. Particular examples could be connected with existing energy sources in the Minipark RES. These batteries differ in design (ie economic parameters), capacity and performance of the battery inverter. The design comes from parameters of emergency system, that should be backuped (emergency elevator, emergency lighting, etc.).

The basic configuration of the designed battery systems is as follows:

1. 36 pc Rolls 4 CS 453 Ah (total $52,2 \mathrm{kWh}, 11 \mathrm{~kW}$ )

2. 72 pc Rolls 4CS 453 Ah (total 104,4 kWh, $11 \mathrm{~kW}$ )

\section{3. $3 \mathrm{ks}$ BlueSky Multigrid 20kWh (total $60 \mathrm{kWh}, 8 \mathrm{~kW}$ )}

The first system corresponds to the typical economic design of a battery for a certain type of building, consumption and installed photovoltaic system. The second option is more economically demanding, but can bring better results in the long operation, as it allows better coverage of peak consumption and at the same time more efficient and economical use of the batteries. The third variant is a purely low cost solution, which would basically function with the shortest time of autonomy.

All variants are in detail analysed in Table VI. Various times of autonomy and system configurations are compared.
Table VI: Time of autonomy

\begin{tabular}{|l|l|l|l|l|l|}
\hline $\begin{array}{l}\text { time } \\
{[\mathrm{d}]}\end{array}$ & $\begin{array}{l}\mathrm{E} \\
{[\mathrm{kWh}]}\end{array}$ & $\begin{array}{l}\mathrm{P} \\
{[\mathrm{kW}]}\end{array}$ & string & $\begin{array}{l}\mathrm{E}_{\text {miss }} \\
{[\mathrm{kWh}]}\end{array}$ & $\begin{array}{l}\mathrm{E}_{\text {plus }} \\
{[\mathrm{kWh}]}\end{array}$ \\
\hline 4 & 52,2 & 26,4 & 30 & 40,9 & 23680 \\
\hline 7 & 87 & 18,5 & 21 & 44,6 & 15219 \\
\hline 7 & 87 & 21,1 & 24 & 24,9 & 18053 \\
\hline 8 & 104 & 18,5 & 21 & 0 & 15189 \\
\hline 10 & 122 & 15,8 & 18 & 0 & 12325 \\
\hline 12 & 139 & 15,8 & 18 & 0 & 12293 \\
\hline 15 & 174 & 13,2 & 15 & 0 & 14023 \\
\hline
\end{tabular}

Table VII. shows results of production for the variant 1 . The simulation assumes that the battery is fully charged at the beginning of a cycle and is continuously being charged. Stand by mode of the emergency system requires $14,13 \mathrm{kWh}$.

TableVII: Variant 1 - simulation

\begin{tabular}{|c|c|c|c|c|c|c|c|c|c|}
\hline & $\begin{array}{l}\text { GlobHHor } \\
\text { wWhimr }\end{array}$ & $\begin{array}{l}\text { Ditrthor } \\
\text { wWW/m }\end{array}$ & $\begin{array}{c}\text { T_Amb } \\
{ }^{\prime} \mathrm{C}\end{array}$ & $\begin{array}{l}\text { Globlnc } \\
\text { WWh/m }\end{array}$ & $\begin{array}{l}\text { Globett } \\
\text { kWh/m? }\end{array}$ & $\begin{array}{c}\text { EArray } \\
\text { Whh }\end{array}$ & $\begin{array}{l}\text { E_Grid } \\
\mathrm{kWh}\end{array}$ & $\begin{array}{c}\text { EBatDis } \\
\text { WWh }\end{array}$ & $\begin{array}{c}P R \\
\text { ratio }\end{array}$ \\
\hline January & 25.3 & 13.71 & -0.68 & 52.3 & 51,4 & 991 & 896 & 4.024 & 0.811 \\
\hline February & 44.3 & 22.32 & 0.29 & 77.7 & 76.3 & 1467 & 1341 & 3.038 & 0.817 \\
\hline March & 86.8 & 49.64 & 4.19 & 115.3 & 1127 & 2134 & 1961 & 0.912 & 0.805 \\
\hline April & 125.9 & 65.02 & 9.28 & 140.9 & 137.0 & 2521 & 2316 & 8505 & 0.779 \\
\hline May & 157.7 & 76.88 & 13.74 & 152.1 & 147.5 & 2654 & 2429 & 2.319 & 0.756 \\
\hline June & 165.6 & 83.30 & 17.10 & 152.2 & 1475 & 2631 & 2406 & 0.568 & 0.748 \\
\hline July & 168.1 & 83.05 & 18.97 & 157,7 & 1528 & 2693 & 2465 & 0.830 & 0.740 \\
\hline August & 142.6 & 67.59 & 18.74 & 150.9 & 146.6 & 2577 & 2363 & 0.535 & 0.741 \\
\hline September & 96.4 & 50.74 & 13.74 & 119.6 & 116.4 & 2103 & 1926 & 2295 & 0.762 \\
\hline October & 58.8 & 3729 & 9.06 & 85.5 & 83.5 & 1564 & 1424 & 0.074 & 0.789 \\
\hline November & 28.1 & 17.95 & 428 & 48.5 & 47.5 & 903 & 805 & 0.000 & 0.786 \\
\hline December & 19.3 & 12.74 & 0.75 & 39.9 & 39.0 & 763 & 680 & 0.000 & 0.808 \\
\hline Year & 1118.8 & 580.22 & 9.17 & 12927. & 1258.1 & 23001 & 21012 & 23.100 & 0.770 \\
\hline
\end{tabular}

Table VIII. shows similar results of production for the variant 2 . The simulation again assumes that the battery is fully charged at the beginning of a cycle and is continuously being charged. Stand by mode of the emergency system requires in this case $18,34 \mathrm{kWh}$.

TableVIII: Variant 2 - simulation

\begin{tabular}{|l|c|c|c|c|c|c|c|}
\hline & $\begin{array}{c}\text { GlobHor } \\
\text { kWh/m }\end{array}$ & $\begin{array}{c}\text { GlobEff } \\
\text { kWh/m }\end{array}$ & $\begin{array}{c}\text { E_Avail } \\
\mathrm{kWh}\end{array}$ & $\begin{array}{c}\text { EUnused } \\
\mathrm{kWh}\end{array}$ & $\begin{array}{c}\text { E_User } \\
\mathrm{kWh}\end{array}$ & $\begin{array}{c}\text { E_Load } \\
\mathrm{kWh}\end{array}$ & $\begin{array}{c}\text { Solfrac } \\
\text { ratio }\end{array}$ \\
\hline January & 25.3 & 51.4 & 115.7 & 0.017 & 347.5 & 341.7 & 0.270 \\
February & 44.3 & 76.3 & 173.7 & 0.000 & 312.7 & 308.7 & 0.501 \\
March & 86.8 & 112.7 & 253.7 & 0.027 & 345.1 & 341.7 & 0.623 \\
April & 125.9 & 137.0 & 299.9 & 0.017 & 333.9 & 330.7 & 0.824 \\
May & 157.7 & 147.5 & 314.6 & 0.027 & 344.8 & 341.7 & 0.794 \\
June & 165.6 & 147.5 & 311.6 & 0.009 & 333.7 & 330.7 & 0.941 \\
July & 168.1 & 152.8 & 319.2 & 0.034 & 345.1 & 341.7 & 0.812 \\
August & 142.6 & 146.6 & 305.8 & 0.010 & 344.9 & 341.7 & 0.813 \\
September & 96.4 & 116.4 & 249.5 & 0.000 & 334.2 & 330.7 & 0.680 \\
October & 58.8 & 83.5 & 184.8 & 0.000 & 345.6 & 341.7 & 0.480 \\
November & 28.1 & 47.5 & 104.7 & 0.000 & 336.1 & 330.7 & 0.243 \\
December & 19.3 & 39.0 & 88.5 & 0.036 & 347.9 & 341.7 & 0.134 \\
\hline Year & 1118.8 & 1258.1 & 2721.7 & 0.177 & 4071.5 & 4023.8 & 0.593 \\
\hline
\end{tabular}

\section{Conclusion}

Simulations presented in chapters 3 and 5 demonstrate capabilities of used simulation methods. Fig. 3 proves that the uncertainty of solar simulation is around 1,5\% while Fig. 8 proves the uncertainty of wind simulation is less than $1,9 \%$. 
Application of these simulated data onto hybrid battery system powering emergency lifts and devices installed in the building of Faculty of electrical engineering in Pilsen gives results shown in Table VII and Table VIII.

The most important result is the possibility of power production prediction from solar-eolic system and thus optimisation of the battery charging schema. This could be used either for increasing life of the battery and economical profit or for optimisation of battery sizing, what again brings economical profit.

\section{References}

[1] M. Belik, Weather dependent mathematical model of photovoltaic panels, Renewable Energy \& Power Quality Journal (RE\&PQJ),698-701 (2017).

[2] M. Belik, Detection and prediction of photovoltaic panels malfunctions, Renewable Energy and Power Quality Journal (RE\&PQJ),544-548 (2018).

[3] O. Rubanenko and V. Yanovych, "Analysis of instability generation of Photovoltaic power station," in 2020 IEEE 7th International Conference on Energy Smart Systems, ESS 2020 - Proceedings, 2020, pp. 128133

[4] Rubanenko O., Kazmiruk O., Bandura V., Matvichuk V., Determination of optimal transformation ratios of power system transformers in conditions of incomplete information regarding the values of diagnostic parameters. Eastern European Journal of Enterprise Technologies. 2017. № 4. Issue 3-88. P. 66-79

[5] Belik, M., Nohacova, L., Small hydro power plants operating as backup source in local island In Proceedings of the 2019 20th International Scientific Conference on Electric Power Engineering (EPE), 178-183, 2019.

[5] Strnadova, P., Parameter control of small PV power plant, Diploma thesis, Pilsen, 2021 